\title{
GERALDO HORÁCIO DE PAULA SOUZA: A ATUAÇÃO DE UM HIGIENISTA NA CIDADE DE SÃO PAULO. 1925-1945
}

Cristina de Campos ${ }^{1}$

Resumo: Geraldo Horácio de Paula Souza foi um figura de grande destaque dentro da Saúde Pública brasileira, porém muito pouco estudada e citada pela bibliografia em História da Ciência. O objetivo deste artigo é trazer aos leitores informações sobre a atuação profissional deste médico e os motivos que o levaram a institucionalizar, em São Paulo, a Saúde Pública como disciplina acadêmica.

Unitermos: Higiene; História da Ciência; Cidade de São Paulo; Urbanismo Higienista; Urbanismo moderno; Movimento sanitarista.

\section{Introdução}

Este artigo tem como objetivo trazer novos dados sobre a vida e obra do médico sanitarista Geraldo Horácio de Paula Souza, atuante na cidade de São Paulo entre as décadas de 1920 e 1940.

A vida e a atuação profissional deste médico é também o objeto central de nossa pesquisa de mestrado, que está nos fornecendo dados importantes para que possamos esclarecer alguns pontos obscuros sobre a história da urbanística moderna em São Paulo, mais precisamente no período da mudança do foco de orientação do planejamento urbano do urbanismo

\footnotetext{
1 Mestranda no Programa de Pós-Graduação em Estruturas Ambientais Urbanas da Faculdade de Arquitetura e Urbanismo da Universidade de São Paulo - FAUUSP- e bolsista Fapesp.
} 
higienista fundamentado nas Ciências Médicas, para o modelo de urbanismo voltado para a "modernização" da cidade.

Compreendendo melhor a atuação de Paula Souza e as suas realizações enquanto diretor do Instituto de Higiene e do Serviço Sanitário Estadual, entenderemos aqui como a Higiene deixou o centro das decisões urbanas, um dos motivos que levaram o próprio Paula Souza a institucionalizá-la como disciplina acadêmica.

\section{A formação profissional de Geraldo Paula Souza.}

Entre 1906 e 1908, Geraldo Paula Souza cursou Farmácia pela Escola de Farmácia de São Paulo, e entre 1908 e 1913 Medicina pela Faculdade de Medicina do Rio de Janeiro, além de neste mesmo período durante as férias, ter tido uma breve formação em Química pela Escola Politécnica paulista com o auxílio do professor Roberto Hottinger. Vale salientar que, em 1911, Paula Souza esteve na Europa realizando cursos e estágios em laboratórios de cidades da Alemanha e da França. Ao concluir o curso de Medicina em 1913, inicia trabalho no laboratório de Hottinger, ajudando a desenvolver o filtro de água Salus. Em 1914, Paula Souza consegue o seu primeiro trabalho, através de uma indicação, na recém-criada Faculdade de Medicina e Cirurgia de São Paulo como assistente da Cadeira de Química. No desempenho desta função, Paula Souza permanece até 1917, quando é chamado para ocupar o cargo de professor substitutivo de Higiene e auxiliar do professor norteamericano Samuel Taylor Darling na mesma instituição onde já trabalhava. Em 1918, foi escolhido para realizar um curso de especialização em Higiene e Saúde Pública, em nível de doutorado, na Universidade Johns Hopkins de Baltimore, Estados Unidos.

É justamente neste curso que Paula Souza irá receber a base de seus conhecimentos em Higiene e Saúde Pública que o acompanharam pelo resto de sua vida, inclusive, irá tratar de 
implantar em São Paulo tanto os novos preceitos de Higiene como também o modelo adotado pelo sistema de Saúde Pública norte-americano.

\section{A Reforma de 1925}

De volta ao Brasil, em 1921, após um período de dois anos de estudo sobre Higiene e Saúde Pública nos Estados Unidos, Paula Souza assume a Cadeira de Higiene na Faculdade de Medicina de São Paulo e a direção do Instituto de Higiene, ainda vinculado a esta instituição. Em 1922, é chamado para dirigir o Serviço Sanitário do Estado de São Paulo e em 1925 realiza uma grande reforma nesta instituição pública com a promulgação do novo Código Sanitário, que segundo Ribeiro (1993), diferenciava-se dos demais códigos anteriores por estar centralizado basicamente na cidade de São Paulo e não nos problemas rurais do interior paulista. De inovação, o novo Código Sanitário de Paula Souza trazia também a mudança de atitude quanto ao foco de intervenção no combate às doenças e epidemias urbanas. Estas agora são atribuídas exclusivamente aos indivíduos e a sua falta de hábitos de higiene que ajudava na proliferação das doenças dentro da cidades. Para corrigir o problema, o Código de 1925 sugeria a adoção de um programa de Educação Sanitária para os habitantes da cidade, realizado através dos Educadores Sanitários e dos Centros de Saúde.

Nas unidades dos Centros de Saúde espalhadas por toda a cidade, os educadores sanitários estariam incumbidos de ensinar aos usuários dos mesmos os preceitos básicos de Higiene e caso estes não pudessem deslocar-se até os Centros, os educadores iriam até suas residências para ensinar novos hábitos de higiene. Este Código Sanitário inovador, alvo de várias críticas, foi logo substituído por um outro Código Sanitário em 1927, ano em que Paula Souza deixa também a direção do Serviço Sanitário.

Apesar da derrota do Código de 1925, Paula Souza conseguiu manter nas dependências do Instituto de Higiene, o 
Centro de Saúde Modelo e o curso de Educadoras Sanitárias, remanejadas para outras unidades de ensino infantil. Tanto a idéia dos Centros de Saúde como também o próprio conceito de Educação Sanitária foram trazidos dos Estados Unidos por Paula Souza, pois quando lá esteve vivenciou esta prática de Saúde Pública. No entanto, na sua tentativa de aplicá-los em São Paulo, desconsiderou fatores sociais e políticos que distanciam a sociedade brasileira da norte-americana.

\section{A Reforma de 1925 e a nova maneira de conceber a cidade}

Conforme vimos no tópico acima, a reforma do Serviço Sanitário realizada por Paula Souza diferenciava-se dos Códigos Sanitários anteriores por ter como proposta não mais o meio e sim o indivíduo. No final do século XIX e início do século XX, tanto na reforma como na construção da nova cidade brasileira, procurava-se sanear o meio pois assim seria evitada a proliferação de uma série de doenças contagiosas. Fortemente embasado na Higiene e nas Ciências Médicas, o urbanismo higienista praticado neste período era defendido por médicos e engenheiros como uma solução eficaz contra as epidemias que assolavam as cidades brasileiras.

Com a realização do saneamento de uma boa parte das grandes cidades brasileiras, especialmente São Paulo, era chegado o momento de centrar os esforços em um outro tipo de infra-estrutura urbana que fizesse com que a cidade comportasse o desenvolvimento das próximas décadas (Freire, 1911). Dessa forma, o urbanismo higienista ${ }^{2}$ deixa de ser o referencial para a cidade, cedendo lugar para o urbanismo moderno, voltado para o progresso e o desenvolvimento. O urbanismo moderno está fundamentado na técnica e nos novos conhecimentos científicos

\footnotetext{
2 Podemos e devemos incluir a palavra "moderno" dentro do urbanismo higienista porque este compreendia uma série de novas teorias e técnicas construtivas. Sobre isto ver Andrade (1991).
} 
produzidos exclusivamente pela Engenharia. Como fruto desta nova concepção urbanística temos a publicação do Plano de Avenidas, em 1929, do engenheiro municipal Francisco Prestes Maia, que privilegiava neste plano urbanístico para a cidade de São Paulo questões como a abertura de novas vias e a circulação de mercadorias dentro da cidade (Leme, 1991).

A Higiene, a partir da década de 1930, será paulatinamente retirada do centro das decisões urbanas em São Paulo. Mas, enquanto área de saber ela se faz presente nas concepções defendidas por Geraldo Paula Souza. Este, assim como os higienistas atuantes em São Paulo no início do século XX não eram partidários das correntes do urbanismo higienista que defendia a intervenção e a correção do meio urbano para se obter a cidade salubre. Esta constatação obtivemos com a leitura da seguinte fala de Paula Souza:

"Coloquemos o caboclo ignorante na casa do patrão e este na choça do caboclo, ou o proprietário de Higienópolis no cortiço do Brás e a família inculta no palácio do primeiro, e observe o acerto do que afirmo: Rápida seria a transformação da choça e do mucambo em locais compatíveis com a vida digna bem como a da casa grande e do palácio nos mais perigosos antros da doença e da miséria."(RIBEIRO, 1991: 304).

Com esta frase, cujo evidente preconceito social não pode ser ignorado, Paula Souza defende, no entanto, que não importa a localização ou mesmo a recolocação dos habitantes "ignorantes" dentro da cidades, pois consigo sempre estarão arrastando a falta dos hábitos de higiene. A realização de planos urbanísticos para oferecer um assentamento salubre, conforme preconizava o urbanismo higienista, também é criticada Geraldo Paula Souza como ineficiente, caso não viesse acompanhada de uma prática constante de educar higienicamente a população urbana. 


\section{Conclusões}

Até aqui, podemos observar que Paula Souza acreditava ser a educação de vital importância para a manutenção de uma vida saudável dentro da cidade brasileira. Para ele, toda a população, principalmente aquela parcela pobre, deveria ser educada a fim de receber todos os preceitos básicos de Higiene para que pudessem desfrutar de um "morar higienizado" dentro da cidade.

O urbanismo moderno de certa forma não privilegiava a Higiene, pois conforme explica Victor da Silva Freire em seu artigo de 1911, Melhoramentos em São Paulo, a fase do saneamento já tinha sido concluída. Era preciso dedicar-se agora ao desenvolvimento da cidade, e principalmente às questões relacionadas à abertura de novas vias de circulação. Com isto, a prática da Higiene ficou adscrita exclusivamente aos médicos. Geraldo Paula Souza tratou então de difundí-la através do Código Sanitário de 1925. Com a recusa da adoção deste código e o seu afastamento do Serviço Sanitário estadual, ou seja, do centro das decisões públicas sobre os problemas urbanos, restou a Paula Souza a divulgação da Higiene através de uma outra instituição, responsável pela criação de novos cursos, formação de técnicos e também o fornecimento de orientações básicas de saúde para a população. O Instituto de Higiene, criado justamente para manter viva a necessidade dos aprendizados básicos de Higiene e Saúde Pública desempenhou este papel até 1945 e mesmo posteriormente quando foi transformado pelas mãos de Paula Souza em Faculdade de Saúde Pública, vindo a pertencer à Universidade de São Paulo.

Esta forma de continuidade dos princípios de Higiene através da institucionalização da Saúde Pública como disciplina acadêmica, permite que se compreenda melhor as circunstâncias e as características que assumiu depois o sistema de saúde no Estado de São Paulo. 


\section{Agradecimentos}

- Professora Doutora Maria Lucia Caira Gitahy, do Departamento de História da Arquitetura da Faculdade de Arquitetura e Urbanismo da Universidade de São Paulo.

- Sra. Ada Celina Paula Souza Anhaia Mello;

- Faculdade de Saúde Pública da Universidade de São Paulo;

- Biblioteca da Faculdade de Arquitetura e Urbanismo da Universidade de São Paulo;

- Fundação de Amparo à Pesquisa do Estado de São Paulo FAPESP

\section{Bibliografia}

ANDRADE, Carlos Roberto Monteiro de. "O Plano de Saturnino de Brito para Santos e a construção da cidade moderna no Brasil." In: Espaço e Debates, São Paulo, 1991. (no 34)

BENEVOLO, L. As origens da urbanística moderna. São Paulo: Martins Fontes, 1994.

CANDEIAS, N. M. F. "Memória Histórica da Faculdade de Saúde Pública da Universidade de São Paulo - 1918-1945" In: Revista de Saúde Pública. São Paulo: ํo 18 (nº especial), 1984.

FREIRE, Victor da Silva. "Melhoramentos em São Paulo" In:

Revista Politécnica. São Paulo:n.33, p. 91-145, fev/mar 1991. GITAHY, Maria Lucia Caira. "Os trabalhadores da construção civil na belle époque" In: Anais do II Congresso Brasileiro de História Econômica. Niterói: ABPHE/UFF, 1997.

JULIÃO, Letícia. Belo Horizonte: itinerários de uma cidade moderna, 1891-1920. Belo Horizonte: UFMG, 1992. (Dissertação de mestrado)

MARX, K. "A assim chamada acumulação primitiva" In: O Capital. São Paulo: Nova Cultural, 1988. 
LABRA, M. E. Movimento sanitarista nos anos 20: da conexão sanitária internacional a especialização em saúde pública no Brasil. Rio de Janeiro: S.N., 1985.

LEME, M.C.S. Revisão do Plano de Avenidas. Um estudo sobre planejamento urbano em São Paulo. 1930. São Paulo: "A formação do pensamento urbanístico, em São Paulo, no início do século XX." In: Espaço e debates. São Paulo: novembro de 1991, ํㅡ 34 .

"A formação do urbanismo como disciplina e profissão: São Paulo na primeira metade do século XX" In: RIBEIRO, L.C.Q. e PECHMAN, R.M. Cidade, povo e nação.

Rio de Janeiro: Civilização Brasileira, 1996.

RIBEIRO, M. A. R. História sem fim... Um inventário da Saúde Pública. São Paulo, 1880-1930. São Paulo: Editora da Unesp, 1993.

SOUZA, G.H. de P. e VIEIRA, F.B. Centro de Saúde. "Eixo" da

Organização Sanitária. São Paulo: Imprensa Oficial do Estado, reedição de 1944.

TOLEDO, B.L. Prestes Maia e as origens do urbanismo moderno.

São Paulo: Editora Empresa das Artes, 1996.

VASCONCELLOS, M. P. C. Memórias da Saúde Pública. A fotografia como testemunha. São Paulo: Hucitec/Abrasco, 1995.

Abstract: Geraldo Horácio de Paula Souza was a person of great prominence inside of the brazilian Public Health, although there are very few studies and bibliographical citations about him in History of Science. The objective of this article is to bring to the readers information on this doctor's professional performance and the reasons that took him to the institutionalization, in São Paulo, of the Public Health as an academic discipline.

Keywords: Hygiene; History of Science; City of São Paulo; Hygienist Urbanism; Modern Urbanism; Hygienist Movement. 